\title{
An Analysis of Commuter Rail Real-Time Information in Boston
}

\author{
Dr. Candace Brakewood \\ City College of New York \\ Dr. Francisca Rojas \\ Inter-American Development Bank \\ Dr. P. Christopher Zegras \\ Massachusetts Institute of Technology \\ Dr. Kari Watkins \\ Georgia Institute of Technology \\ Joshua Robin \\ Masabi LLC
}

\begin{abstract}
Prior studies have assessed the impacts of real-time information (RTI) provided to bus and heavy rail riders but not commuter rail passengers. The objective of this research is to investigate the benefits of providing commuter rail RTI. The method is a three-part statistical analysis using data from an on-board survey on two commuter rail lines in the Boston region. The first analysis assesses overarching adoption, and the results show that one-third of commuter rail riders use RTI. The second part conducts difference of means tests and regression analysis on passenger wait times, which reveals that riders' use of RTI is correlated with a decrease in self-reported "usual" wait times. The third part analyzes 12 quality-of-service indicators, which have a limited relationship with RTI utilization. The results suggest that the benefits of commuter rail RTI are modest. Despite this, many commuter rail riders choose to use this new information source, which has important implications for transit managers considering deploying RTI systems.
\end{abstract}

\section{Introduction}

Public transit providers often struggle with service reliability issues; when a transit vehicle does not arrive on time, passengers become frustrated and may be less likely to choose transit for future trips. Reliability can be improved in many ways, including improving rights-of-way, using service planning approaches, or implementing control strategies. While these supply-side strategies can be effective at improving reliability, they often come at a substantial cost. 
As another way to address reliability concerns, transit agencies in the United States increasingly provide real-time vehicle location and/or arrival information (RTI) to riders. Providing RTI helps passengers adapt to the unreliability of transit service (Carrel et al. 2013). Moreover, RTI can be provided to passengers in an increasingly cost-effective manner. Over the past decade, the provision of RTI to passengers via web-enabled and/ or mobile devices has become ubiquitous in urban bus and rail systems (Schweiger 2011; Rojas 2012).

This trend has spurred commuter rail operators to consider providing riders with similar levels of digital, dynamic transit information. Recently, some of the largest commuter rail providers in the U.S. have begun to offer RTI to passengers. Both the Long Island Rail Road and Metro-North Railroad in the New York region provide real-time train location information on a website known as "Train Time" (MTA 2013a; MTA 2013b). Similarly, New Jersey Transit provides information through its "Departure Vision" real-time train status service (New Jersey Transit 2013), and, in the Chicago region, Metra offers real-time train tracking on its website (Metra 2013).

In Boston, the Massachusetts Bay Transportation Authority (MBTA) has taken a different approach to commuter rail RTI. Instead of developing its own RTI platform, it released real-time commuter rail data to independent software developers, which has resulted in numerous third-party RTI applications on many different digital platforms, including websites and smartphone applications. Since commuter rail operators increasingly offer RTI options to passengers, this research aims to assess how riders may benefit from this information.

\section{Prior Research}

While the delivery of RTI has been possible for decades, until recently, such information tended to be delivered via electronic signs at stations, if at all. Two inter-related phenomena in the U.S. have begun to change this fixed-infrastructure, centrally-provided information model: the "open data" movement and the rapid adoption of the "smartphone." The results are increasingly available transit information in a variety of formats for connected devices (Schweiger 2011).

In light of this trend, a growing body of literature has begun to assess the benefits of providing RTI to transit riders via web-enabled and/or mobile devices. This brief literature review focuses on prior research that uses actual behavioral data to understand rider benefits, since this will most likely provide more concrete conclusions needed to inform decision-makers. Prior studies that use stated preference methods (e.g., Tang and Thakuriah 2010) or simulation techniques (e.g., Cats et al. 2011; Fries et al. 2011; Fonzone and Schmöcker 2014) to evaluate the potential impacts of RTI on passenger behavior are not included in this review. Following the framework of a prior RTI study in Tampa, Florida (Brakewood, Barbeau, and Watkins 2014), this literature review divides potential rider benefits of RTI into three key areas: (1) decreased wait times, (2) increased satisfaction with transit service, and (3) increased ridership. 


\section{Decreased Wait Times}

$\mathrm{RTI}$ enables riders to "time" their arrival at a stop/station to minimize wait time. Using RTI improves passenger awareness of the estimated actual arrival time of the vehicle at the stop/station, thus allowing them to more precisely time their arrival at the station and reduce wait time. Additionally, RTI may reduce passenger perception of waiting time once they have reached a stop/station because they are getting real-time updates of when the vehicle should arrive.

A recent study conducted in Seattle found that bus riders with RTI perceived wait times at the bus stop to be approximately 30 percent less than those who did not use RTI, and the actual wait times of RTI users were almost two minutes less than the wait times of non-users (Watkins et al. 2011). Another study of bus riders in Tampa found significant improvements in the "waiting experience" associated with use of mobile RTI, including reductions in self-reported wait times and decreases in levels of anxiety and frustration while waiting for the bus (Brakewood, Barbeau, and Watkins 2014).

\section{Increased Satisfaction}

If transit passengers spend less time waiting and/or perceive waiting time to be less, they may become more satisfied with overall transit service. A panel study conducted of the shuttle bus system on the University of Maryland campus showed increased satisfaction with transit service attributable to RTI (Zhang et al. 2008). Additionally, the results of two surveys of bus riders in Seattle who use mobile RTI revealed increased satisfaction with overall bus service (Ferris et al. 2010; Gooze et al. 2013).

\section{Increased Ridership}

If passengers spend less time waiting and/or are more satisfied with transit service, then RTI may increase the frequency of transit trips by existing passengers or potentially attract completely new riders to transit. In Chicago, a longitudinal analysis of bus ridership over a nine-year period found a modest increase in route-level ridership attributable to the provision of bus RTI (Tang and Thakuriah 2012). A follow-up study in Chicago found a small increase in train ridership over a six-year period attributable to the provision of bus RTI, possibly due to increased intermodal transfer efficiency between trains and buses (Tang et al. 2013).

\section{Summary of Prior Research}

This review of studies grounded in behavioral data reveals three key rider benefits of RTI: (1) decreased wait times, (2) increased satisfaction with transit service, and (3) increased ridership. However, these benefits were identified based primarily on studies of bus and urban rail systems, leaving at least one transit mode understudied: commuter rail. Commuter rail may be understudied for numerous reasons. First, bus and heavy rail systems carry the majority of public transit trips in the U.S. (APTA 2012); therefore, these systems may be studied more frequently simply because they are more heavily used. In addition, commuter rail systems generally operate at longer headways and run on dedicated rightof-way, whereas urban bus systems often have shorter headways and operate in mixed traffic. Because of differences in frequency and reliability of service, the value of using RTI on urban bus systems may be different (likely greater) than for commuter rail systems, which may be why they have been studied first. Regardless, by focusing on a mode that 
has been largely excluded from previous research, this study adds to our understanding of RTI provision in transit systems.

\section{Objectives}

The overall objective of this research is to explore the utilization and passenger benefits of RTI provided to commuter rail riders through web-enabled and/or mobile devices. Three specific objectives are set forth, which focus on measures of RTI use and benefits in the short term. First, the overall levels of adoption and rates of utilization of commuter rail $\mathrm{RTI}$ are explored. Second, prior research indicates that reductions in passenger wait times are an important benefit of RTI in other modes of transit; subsequently, this study aims to determine if there are decreases in wait times associated with using commuter rail RTI. Third, the literature review revealed that increases in satisfaction with transit service are another possible benefit of RTI systems; therefore, this study aims to assess if there are increases in quality of service ratings associated with using RTI. It should be noted that the literature review suggested that increased ridership is a benefit of RTI; such analyses, however, require longitudinal analysis and are left for future research in the commuter rail case.

\section{Background}

Commuter rail service in Greater Boston includes fixed schedule, daily service on 12 heavy rail lines serving downtown Boston via 2 central city stations (North Station and South Station). Boston has the fifth largest commuter rail ridership in the U.S. based on the number of unlinked passenger trips (APTA 2012). The service is operated by the Massachusetts Bay Commuter Rail Company (MBCR) under contract with the Massachusetts Bay Transportation Authority (MBTA).

Three basic categories of information sources are available to commuter rail riders in Boston: (1) static information, (2) service alerts, and (3) real-time information. Static information consists of schedules and maps, which generally are updated on a quarterly or annual basis and are available online at the MBTA's website, through other websites (such as Google Transit, a free trip planner available worldwide), in printed form, and on signs at stations. Service alerts, known as "T-alerts" in Boston, include emails and text messages that report major delays (more than 15 minutes) to subscribers. Riders can sign up for mode- and line-specific alerts, which are automatically pushed to their mobile phone or email account in the event of a delay (MBTA 2013). Service notifications are also posted on the MBTA's website. Real-time information (RTI) refers to up-to-the-minute tracking of transit vehicle locations and often includes predicted arrival times for stops/stations. RTI is distinguished from service alerts because the latter are incident-based information "pushed" to the user, while the former are user-initiated inquiries to the system. RTI has increasingly become available to riders "on-the-go" due to the advent and widespread adoption of smartphones and smartphone-based applications ("apps") and the "open data" movement.

In the U.S., the MBTA was an "early adopter" in the movement towards public disclosure of real-time data (Rojas 2012), gradually releasing real-time data to the public for each transit mode as part of the Massachusetts Department of Transportation's open data 
initiative (MassDOT 2013) (Figure 1). In 2009, the MBTA released a real-time data feed for five "pilot" bus routes that included vehicle location and arrival information. In response to public demand, real-time data were released for all approximately 200 MBTA-operated bus routes in the summer of 2010. Shortly thereafter, the MBTA began publishing realtime data for the heavy rail lines (excluding the light rail Green Line). In June 2011, the MBTA added commuter rail to its real-time data initiative as a beta feed, which used a GPS-based tracking system originally designed for automated on-board announcements and station signage. Prior to the open release of data to third-party developers, LED signs at some commuter rail stations gave riders real-time updates by displaying "train approaching" messages.

\begin{tabular}{|c|c|c|c|}
\hline FALL 2009 & SUMMER 2010 & FALL 2010 & JUNE 2011 \\
\hline $\begin{array}{l}\text { Real-time location \& } \\
\text { predicted arrival data } \\
\text { released for } 5 \text { MBTA } \\
\text { bus routes } \\
\text { (pilot program) }\end{array}$ & $\begin{array}{l}\text { Real-time location \& } \\
\text { predicted arrival data } \\
\text { released for all } \\
\sim 200 \text { MBTA operated } \\
\text { bus routes }\end{array}$ & $\begin{array}{l}\text { Real-time location } \\
\& \text { predicted arrival } \\
\text { data released for Red, } \\
\text { Orange and Blue } \\
\text { subway lines }\end{array}$ & $\begin{array}{l}\text { Real-time location } \\
\text { \& predicted arrival } \\
\text { data released for all } \\
\text { Commuter Rail lines }\end{array}$ \\
\hline
\end{tabular}

FIGURE 1. Timeline of transit data release in Boston

Similar to other transit agencies, the MBTA makes available on its website the independently-developed applications (without endorsement) that draw from the real-time data feeds. On the MBTA's webpage, more than 80 different web and mobile applications created by third-party software developers are showcased (as of 2014), and many of them integrate commuter rail data (MBTA 2014). Despite the great variety of transit information applications now available, little evidence exists on how many riders in Boston actually use RTI or how they access it, partly because the applications come from third parties instead of the MBTA. Therefore, this research aims to provide a more concrete understanding of RTI utilization on Boston's commuter rail system.

\section{Data Collection}

Data for this analysis were collected via a short paper survey administered in June 2012. An on-board sampling method was selected to most easily reach the target population (commuter rail riders). This study does not explicitly attempt to detect potential modal shifts (e.g., from car to commuter rail), since the data collection was conducted only one year after the debut of the commuter rail RTI feed. Furthermore, capturing non-users of commuter rail would have required a sampling strategy well beyond the resources available.

The on-board survey was conducted on three weekdays in mid-June during the morning and evening peak periods (between 6:30-10:00 AM and 4:00-7:30 PM). Because ridership on the commuter rail is highly-peaked in the commuting direction (inbound in the morning, outbound in the evening), the off-peak direction (outbound in the morning, inbound 
in the evening) also was sampled so both peak and off-peak riders could be included in the analysis. Riders were sampled on 12 train trips: 6 outbound and 6 inbound. Once on-board the trains, teams of two to three researchers distributed paper surveys to as many riders as possible and collected them before riders alighted.

\section{Line Selection}

All 12 commuter rail lines could not be sampled due to resource constraints. Instead, two lines were selected - the Worcester and the Newburyport/Rockport lines-based on four factors: geography, ridership levels, ridership demographics, and service reliability. Geography was defined based on the terminal stations in downtown Boston. As two large terminal stations serve different geographic regions in the metropolitan area, one line from each was selected to better represent the entire network. The Newburyport/Rockport line terminates at North Station, and the Worcester line ends at South Station. Second, only high ridership lines were considered, to increase the number of survey responses. The selected lines have average weekday boardings of approximately 17,000-18,000 and are among the highest ridership levels within the overall commuter rail network (MBTA 2010). Third, based on previous survey results, diversity in rider income levels and ethnicities was considered, since these may impact the level of technology adoption and subsequently, utilization of RTI. The Worcester line has relatively high levels of demographic diversity, whereas the Newburyport/Rockport line has a more homogenous, high-income ridership (CTPS 2010). Finally, the two lines differ in levels of service reliability, as defined by the MBTA's on-time performance metric. Monthly data for June 2012 show that the Worcester line was on time for 91 percent of trips, above the commuter rail system average of 89 percent, whereas the Newburyport and Rockport branches had on-time performance measures of only 70 and 61 percent, respectively (MBTA 2012).

\section{Data Collection Constraints}

Although standard survey research procedures were followed, data collection faced constraints. First, no survey mail-back option existed. Riders were instructed to complete as many questions on the survey as possible during their commute, leaving surveys incomplete because the rider alighted the train prior to completion. Additionally, since the survey was administered only in English, a very small number of riders (fewer than 10) declined participation because they did not speak English. Last, due to the constraints of conducting an on-board survey in rail cars (which were often crowded), the rate at which riders accepted or declined participation was not measured.

\section{Survey Content}

The survey instrument included questions about the awareness and use of commuter rail, subway, and bus RTI; 2 questions about wait times; and 12 quality of service indicators. Travel behavior questions about frequency of ridership, trip destination, and boarding and alighting locations, as well as socioeconomic status of respondents, were included to better account for relevant influencing factors. The survey also contained questions about ticketing, which were used in a mobile ticketing analysis (Brakewood et al. 2014). A copy of the questionnaire is available online (Brakewood 2014). 


\section{Responses}

In total, 914 responses were collected during the fieldwork period, with 903 deemed sufficiently complete for the following analysis. Sufficient completeness means that the respondent answered questions up to the halfway point on the questionnaire, where the use of commuter rail RTI question was posed. The survey responses from both lines were pooled and used to conduct the following analyses.

\section{Results}

Three analyses were conducted to explore the impacts of RTI on commuter rail passengers. The first analysis assessed overall adoption and utilization of RTI by commuter rail riders. The second analysis aimed to understand if decreases in wait times are associated with using commuter rail RTI. The third analysis examined if increases in perceived quality of service are associated with using RTI.

\section{Analysis 1: Awareness and Utilization of RTI}

This analysis assessed three different aspects of RTI utilization by commuter rail riders: awareness and adoption of RTI for the three primary MBTA modes (commuter rail, bus, and subway); the interfaces used to access commuter rail RTI; and the reasons riders do not use commuter rail RTI.

\section{Awareness and Utilization of RTI}

Survey respondents were provided with a brief description of RTI and were asked if they were aware of RTI for commuter rail, MBTA buses, and MBTA subway trains. Figure 2 shows that 54 percent of respondents were not aware of commuter rail RTI, 63 percent had not heard of subway RTI, and 66 percent were not aware of bus RTI. Prior to the survey, commuter rail RTI had not been formally marketed by the MBTA or MBCR, likely contributing to the fact that more than half of surveyed riders were not aware of commuter rail RTI. For those who were aware of commuter rail RTI, this was likely due to word-of-mouth, press coverage, and marketing conducted by independent software developers (such as through social media).

FIGURE 2.

Awareness and utilization of RTI by commuter rail riders

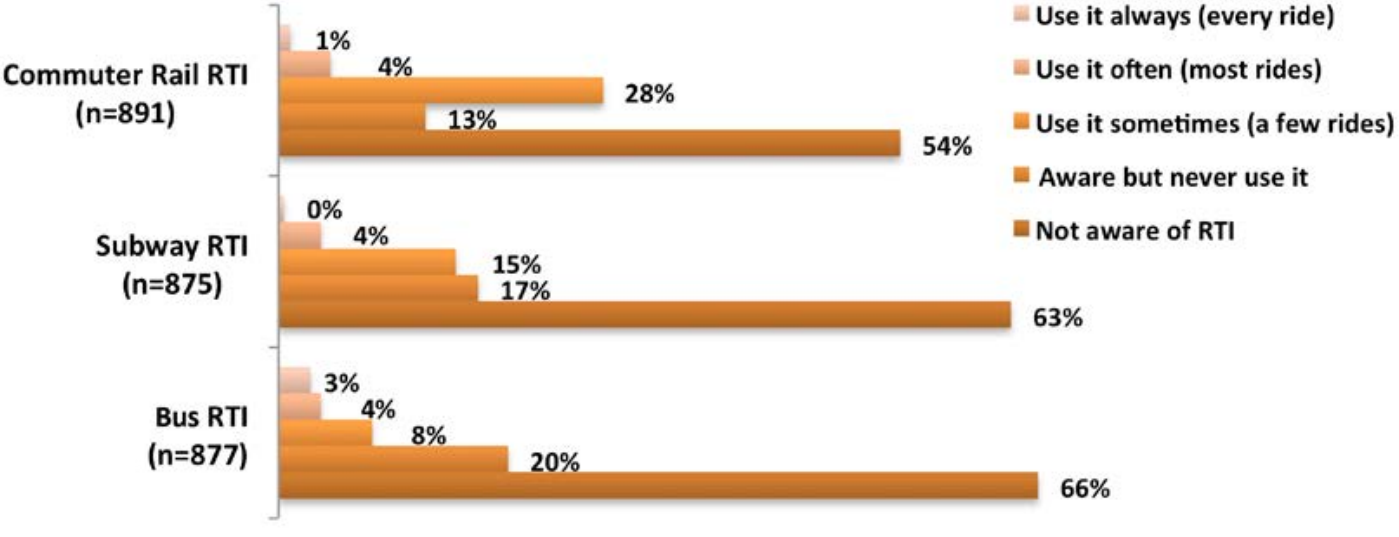

Note: All percentages rounded to the nearest whole number. 
The survey also asked commuter rail riders how frequently they used RTI for each MBTA mode. Figure 2 shows that 33 percent of riders used commuter rail RTI either on every ride (always $=1 \%$ ), on most rides (often $=4 \%$ ), or on a few rides (sometimes $=28 \%$ ). However, 13 percent of surveyed riders were aware of commuter rail RTI but had not used it, and, as previously stated, 54 percent were not aware of commuter rail RTI.

Figure 2 also shows that 19 percent of commuter rail riders had used subway RTI (total of "always," "often," and "sometimes"), and only 15 percent used bus RTI (total of "always," "often," and "sometimes"). A large amount of overlap exists between riders who used commuter rail, bus, and subway RTI: 46 percent of riders who used commuter rail RTI also used either bus, subway, or both bus and subway RTI. This overlap may be attributable to RTI applications that integrate all three modes. At the time of the survey (in 2012), there were 44 third-party applications listed on the MBTA's "App Showcase" website, many of which integrated commuter rail RTI with others modes (Rojas 2012). Additionally, bus and subway data were released prior to the commuter rail data (as shown in Figure 1) and, therefore, bus and subway RTI users may already have had the applications needed to use commuter rail RTI. Note that the on-board survey sampled only commuter rail riders; the utilization of bus and subway RTI would likely be much higher if passengers on subway trains and buses also were sampled. Last, only 5.5 percent of survey respondents reported having used commuter rail RTI prior to boarding the train on the day of the survey.

\section{Interfaces to Access RTI and Reasons for Not Using RTI}

Respondents could select all technologies that they had used to access commuter rail RTI, and they most commonly used a desktop or laptop computer (51\%) (Figure 3). This may be because riders often were traveling to/from work and may have checked the real-time status of their train before leaving their office. The second most-common method was through smartphone applications (36\%).

FIGURE 3. How riders access commuter rail $\mathrm{RTI}(\mathrm{n}=334)$

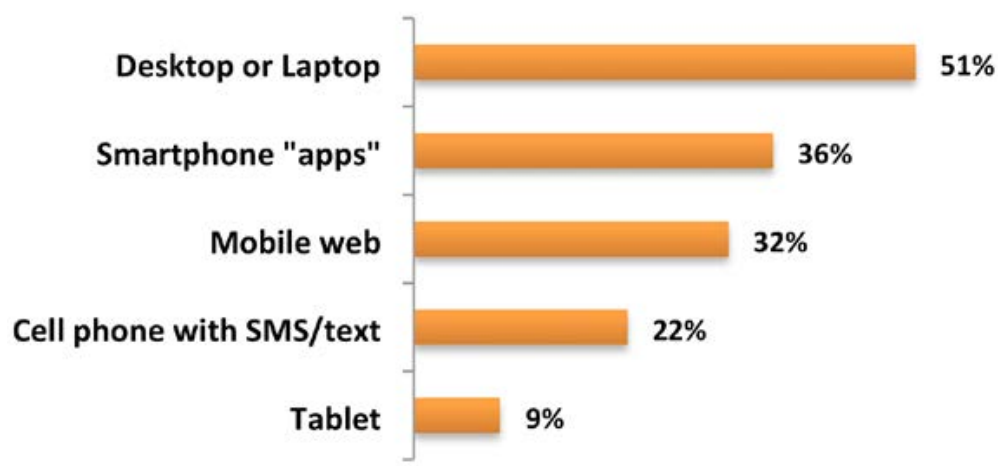

Riders who were aware of commuter rail RTI but stated that they "never" use it were asked why. The most common reason (38\%) for not using commuter rail RTI was "I don't have a smartphone" (Figure 4). Note that all respondents were asked which types of information and communication technologies they had used in the past 30 days, and smartphones had utilization rates of 76 percent of all respondents, a higher rate than the national average (46\%) of smartphone owners at the time of the survey (Pew Research Internet Project 2012). 
FIGURE 4.

Reasons why riders do not use commuter rail $\mathrm{RTI}(\mathrm{n}=144)$

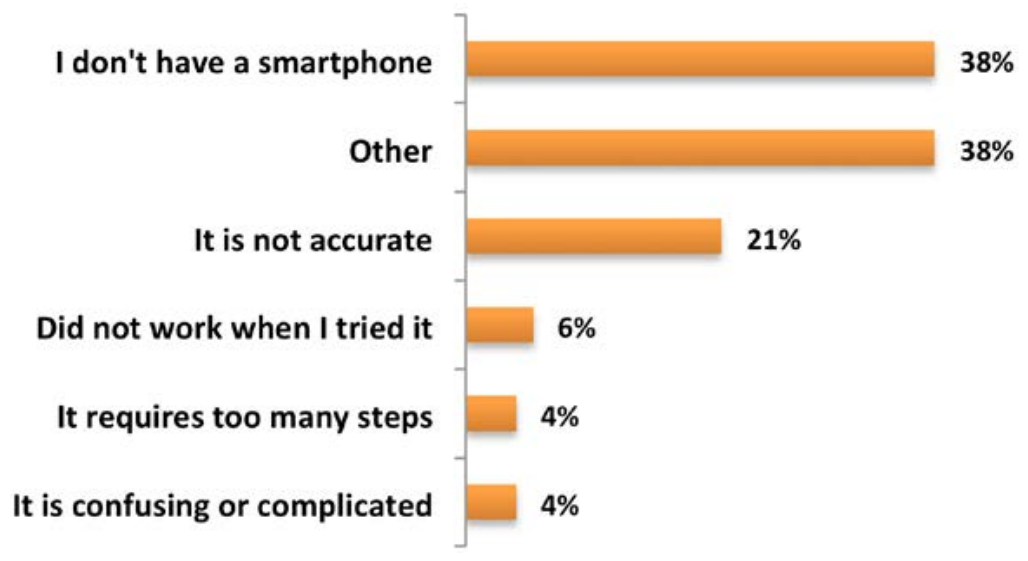

Another common reason for not using commuter rail RTI was "other." This response had a write-in section, and the most frequent theme of write-in comments was that commuter rail RTI was not needed. Some examples of write-in responses include "haven't needed to," "don't see the need to," "not valuable info," and "doesn't matter." These reasons may stem from the nature of commuter rail service, traditionally a fixed-schedule service operating at low frequencies. Commuter rail riders traditionally consult the schedule pre-trip, and riders may continue to be reliant on static schedule information for reasons of habit or simplicity. Additionally, some survey respondents noted the lack of other transportation alternatives in the event of a delay. Since the commuter rail network services many outlying suburbs without other transit options, riders may not have alternative means of getting to their destination if there is a delay in service.

Finally, 21 percent of riders who do not use commuter rail RTI selected the response that "it is not accurate." Unfortunately, the accuracy of RTI was not monitored during the study period.

\section{Analysis 2: Wait Times}

Passenger wait times were analyzed because prior research indicated that reductions in wait times are a key benefit of RTI systems. RTI enables riders to "time" their arrival at the stop/station to minimize wait time. This is particularly important when a vehicle deviates from the posted schedule because passengers can then adjust their behavior to reduce wait time by leaving their origin (e.g., home) earlier or later than if they had simply consulted the schedule. The relationships between RTI use and passenger wait times were tested using difference of means tests and regression analysis.

\section{Wait Time on the Day of the Survey}

The first analysis compared wait times on the day of the survey for passengers who used commuter rail RTI before boarding the train and passengers who did not. Passengers were divided into groups based on their response to the following question: Before boarding the train today, did you use real-time commuter rail information on a phone or the web? [Yes/No]. Wait times came from responses to the following question: How long did you wait at the commuter rail station today? [Write number, e.g., 7 minutes]. 
We hypothesized that RTI use on the day of the survey would be correlated with lower reported wait times because studies of other transit modes have found that passengers wait less with the real-time knowledge of train arrival times and/or they perceive the waiting time to be lower due to the reduced uncertainty about train arrival times. Table 1 shows that the data do not support this hypothesis, since there is no statistically-significant difference in reported wait times on the day of the survey $(p=0.2557)$.

TABLE 1.

Difference of Means Test for Wait Time Today

\begin{tabular}{|l|c|c|c|}
\hline \multicolumn{1}{|c|}{ Group } & Observations & Mean (mins) & Std. Dev. \\
\hline Used real-time information today & 48 & 6.43 & 4.77 \\
\hline Did not use real-time today & 839 & 6.91 & 7.10 \\
\hline Total & 887 & 6.88 & 7.00 \\
\hline $\mathrm{t}=-0.6606, \mathrm{P}(\mathrm{T}<=\mathrm{t})=0.2557$ (one-tail) & \multicolumn{3}{|l}{} \\
\hline
\end{tabular}

Two notes should be made about this analysis. One important variable affecting passenger wait times is the reliability of the trains on the day the survey was administered; therefore, the teams distributing surveys were instructed to note any delays in service. None of the train trips for which the on-board survey was conducted experienced delays. Subsequently, passengers who consulted RTI before boarding would have seen the same information as passengers who consulted traditional information sources (i.e., schedules). Second, there were a few outlier responses to the wait time question (3 respondents said 60 minutes and 1 stated 90 minutes). These outliers were excluded from the analysis because commuter rail trains generally operate at headways less than one hour during the time period when data were collected.

Finally, we specified and estimated an ordinary least squares regression model of wait times on the day of the survey as a function of many variables, including mode used to access the station, line (Worcester, Newburyport/Rockport), time and direction of travel, destination, time sensitivity of the trip (can/cannot be late), use of wait time for other activities (reading/listening to music), frequency of travel on that commuter rail line, use of other information sources (schedules, T-alerts, posted schedules, LED signs), and socioeconomic characteristics of the respondent (gender, age, ethnicity, household income, and household car ownership). The results confirm the previous finding of no statistically-significant difference in self-reported wait times on the day of the survey attributable to use of commuter rail RTI. Subsequently, this model is not shown for presentation.

\section{Usual Wait Time}

The second analysis compared the "usual" wait times of passengers who have used commuter rail RTI to the usual wait times of passengers who have not. Passengers were divided into two groups based on their responses to how frequently they use commuter rail RTI, with the RTI user group consisting of respondents who said they "sometimes," "often," or "always" use commuter rail RTI. The non-user group consisted of all respondents who said they "never" use commuter rail RTI. Usual wait times were measured based on responses to the question: How long do you usually wait at the commuter rail station? [Write number, e.g., 7 minutes]. 
This analysis aimed to capture the difference that RTI could have on passenger wait times over an extended period of time. We hypothesized that passengers who sometimes/ often/always consult RTI would be able to adjust their wait times on days when the commuter rail experienced delays. Subsequently, their "usual" wait times would be less than for riders who consulted only traditional information sources (i.e., schedules). Table 2 shows that the data somewhat support this hypothesis, since the mean usual wait time of $\mathrm{RTI}$ users is almost one minute less than for non-RTI users (7.87 minutes vs. 8.45 minutes), a difference significant at a $90 \%$ confidence level $(p=0.0915<0.1)$.

TABLE 2.

\begin{tabular}{|l|c|c|c|}
\hline \multicolumn{1}{|c|}{ Group } & Observations & Mean (mins) & Std. Dev. \\
\hline Real-time information user & 295 & 7.87 & 5.65 \\
\hline Have not used real-time & 573 & 8.45 & 6.81 \\
\hline Total & 868 & 8.25 & 6.45 \\
\hline $\mathrm{t}=-1.3328, \mathrm{P}(\mathrm{T}<=\mathrm{t})=0.0915$ (one-tail) & \multicolumn{3}{l}{} \\
\hline
\end{tabular}

To control for potentially confounding variables influencing usual wait times, we again estimated an ordinary least squares regression model, with the results shown in Table 3. The independent variables included in different specifications were the same as the previous wait time analysis, plus one additional variable for respondents who sometimes/ often/always consult commuter rail RTI. The overall goodness-of-fit of the model is moderately low (R-squared=0.16), which is not surprising given the individual-level data underlying it.

As can be seen in Table 3, the intercept term (11.92) indicates that when all other variables are zero, the usual wait time is approximately 12 minutes. The first independent variable, Peak, is a binary variable for traveling in the peak direction (inbound in the morning, outbound in the evening). The negative value of the peak direction coefficient $(-3.53)$ shows that respondents who were traveling in the peak direction experience shorter typical wait times. This result may be explained, in part, because the peak direction has shorter headways than corresponding trips in the off-peak direction. The second set of independent variables, Access Mode, reveals that accessing the commuter rail by MBTA-operated bus, subway train, or boat significantly increases the usual wait time, as is indicated by the positive coefficient (1.98). This may be due to poor coordination between different transit modes and/or may result from higher perceived waiting times due to the disutility of transferring between fixed schedule transit services. The third set of variables, Frequency of Commuter Rail Trips, demonstrates that those who ride that commuter rail line more frequently (2-4 days/week or 5+ days/week) report shorter usual wait times. This may indicate that regular riders are more comfortable "cutting it short" or have better knowledge of schedules. The positive coefficient (1.42) for the Trip Destination variable representing home-bound trips indicates that respondents report higher typical wait times when traveling home compared to work-bound trips. The fifth set of variables, Time Sensitivity of the Trip, shows that riders who can be a few minutes late and those who have flexibility report shorter wait times typically. These results suggest that riders with some flexibility wait less, perhaps indicating a difference in perceived wait times 
and/or less concern with missing the train if they "cut it close" getting to the train station. Respondents also were asked how they used their wait time. Those who stated that they use the time to read, make calls, listen to music, etc., typically experienced longer wait times, as indicated by the positive coefficient (1.26). Two possible interpretations of this are that these riders think they spend more time waiting because they are otherwise occupied, or they may choose to wait longer as they find value in the use of that time. The only socioeconomic/demographic characteristic that was statistically significant was the set of variables for Ethnicity. The negative coefficient (-1.28) for Asian riders indicates that they report shorter typical wait times, which requires further investigation.

\begin{tabular}{|c|c|c|c|c|c|}
\hline \multirow{11}{*}{$\begin{array}{r}\text { TABLE } 3 . \\
\text { Regression Model } \\
\text { for Usual Wait Time }\end{array}$} & Category & Independent Variable & Estimate & T-stat & $\begin{array}{l}\text { Robust } \\
\text { T-stat }\end{array}$ \\
\hline & & Intercept & 11.92 & $11.6^{* * *}$ & $9.59^{* * *}$ \\
\hline & Peak Period & $\begin{array}{l}\text { Off-peak trip (reference) } \\
\text { Peak trip (inbound AM; outbound PM) }\end{array}$ & -3.53 & $-6.37^{* * *}$ & $-4.60^{* * *}$ \\
\hline & Access Mode & $\begin{array}{l}\text { Drove/dropped off via car (reference) } \\
\text { MBTA bus/subway train/boat } \\
\text { Walk or bicycle } \\
\text { Other (taxi, shuttle, etc.) }\end{array}$ & $\begin{array}{r}- \\
1.98 \\
-0.36 \\
1.94\end{array}$ & $\begin{array}{l}3.01^{* * *} \\
-0.70^{*} \\
1.84^{*}\end{array}$ & $\begin{array}{c}2.82^{* * *} \\
-0.77^{*} \\
1.86^{*}\end{array}$ \\
\hline & $\begin{array}{l}\text { Frequency of } \\
\text { Commuter Rail Trips }\end{array}$ & $\begin{array}{l}1 \text { day or less/week (reference) } \\
2 \text { to } 4 \text { days/week } \\
5 \text { or more days/week }\end{array}$ & $\begin{array}{r}- \\
-1.74 \\
-1.73\end{array}$ & $\begin{array}{c}- \\
-1.88^{*} \\
-1.96^{* *}\end{array}$ & $\begin{array}{c}- \\
-1.63 \\
-1.68 *\end{array}$ \\
\hline & Trip Destination & $\begin{array}{l}\text { Work (reference) } \\
\text { Home } \\
\text { Other (social/recreational activity, etc.) }\end{array}$ & $\begin{array}{r}- \\
1.42 \\
0.77\end{array}$ & $\begin{array}{l}2.86^{* * *} \\
0.89^{*}\end{array}$ & $\begin{array}{l}- \\
2.78^{* * *} \\
0.77\end{array}$ \\
\hline & $\begin{array}{l}\text { Time Sensitivity } \\
\text { of Trip }\end{array}$ & $\begin{array}{l}\text { I cannot be late (reference) } \\
\text { I can be a few minutes late } \\
\text { I have flexibility }\end{array}$ & $\begin{array}{r}- \\
-1.42 \\
-0.77\end{array}$ & $\begin{array}{l}- \\
-2.87^{* * *} \\
-1.26\end{array}$ & $\begin{array}{l}- \\
-2.83^{* * *} \\
-1.12\end{array}$ \\
\hline & Used Wait Time & $\begin{array}{l}\text { Did not used wait time (reference) } \\
\text { Used wait time to read/make calls/listen to music }\end{array}$ & 1.26 & $2.93^{* * *}$ & $2.96^{* * *}$ \\
\hline & Commuter Rail RTI & $\begin{array}{l}\text { Non-user (reference) } \\
\text { Real-time information user }\end{array}$ & $\begin{array}{r}- \\
-0.80\end{array}$ & $-1.80^{*}$ & $-2.02^{*} * *$ \\
\hline & Ethnicity & $\begin{array}{l}\text { Caucasian (reference) } \\
\text { Asian } \\
\text { Other ethnicity }\end{array}$ & $\begin{array}{r}- \\
-1.28 \\
1.08 \\
\end{array}$ & $\begin{array}{c}- \\
-1.90 * \\
1.29\end{array}$ & $\begin{array}{r}- \\
-2.09 \\
1.15\end{array}$ \\
\hline & Summary Statistics & $\begin{array}{l}\text { number of observations } \\
\text { degrees of freedom } \\
\text { F-statistic } \\
\text { R-squared } \\
\text { Adjusted R-Squared }\end{array}$ & & $\begin{array}{c}811 \\
796 \\
11.05 \\
0.1627 \\
0.1480\end{array}$ & \\
\hline
\end{tabular}

Significance codes: ${ }^{*} p<0.1,{ }^{* *} p<0.05,{ }^{* * *} p<0.01$

Most importantly for this research, the binary variable representing Use of Commuter Rail RTI reveals that RTI users typically experience shorter wait times. The magnitude of the coefficient $(-0.80)$ implies that RTI users report that they typically wait, on average, about 1 minute less than non-users, which is approximately 10 percent of the average usual wait time. 
In light of the statistically-significant relationship between the use of commuter rail RTI and usual wait times, two important caveats should be made. First, the survey instrument had free-form responses for both questions about wait time (today and usual). For the usual wait time question, many respondents wrote in a range (e.g., 8-10 minutes), as opposed to writing in a single number (e.g., 7 minutes), and when a range was provided, the average of the range was used. Future research should aim to more clearly capture this concept, since it may be indicative of the inherent variability of wait times. Second, as was previously noted, wait times used in both analyses were self-reported. Prior research has shown that self-reported wait times may not align with actual wait times due to the perception of time (Watkins et al. 2011). Accordingly, the finding that the usual wait times of RTI users were less than the usual wait times of non-users could actually be a difference in the perception of wait time attributable to RTI. To differentiate between the two (actual and perceived wait times), independent observations of passenger wait times would be necessary.

\section{Analysis 3: Quality of Service}

The third analysis pertains to the quality of transit service, since prior work revealed that increases in satisfaction with transit service are another possible benefit of RTI systems. Tables 4 and 5 show the results of the quality-of-service analysis that tests the differences between RTI users (defined previously as "sometimes," "often," or "always" using commuter RTI) and non-RTI users (defined as "never" using commuter rail RTI). The survey included nine specific elements of transit service (\#1-6 in Tables 4 and \#7-9 in Table 5) and three overall quality of service indicators (\#10-12 in Table 5). Respondents ranked all 12 indicators on 5-point scales from "poor" to "excellent." Some of these indicators were selected because of their use on previous MBTA surveys (CTPS 2010) and others were added to capture topics related to information provision, particularly RTI and T-alerts.

Tables 4 and 5 show the count and percentage of survey responses for each quality-of-service indicator for non-users, RTI users, and their combined total. Additionally, the percent above average (good/excellent) is shown for non-users, RTI users, and their combined total. The results of chi-squared tests used to assess differences between RTI users and non-users are also shown.

Overall, the analysis shows limited relationships between the quality-of-service indicators and the use of commuter rail RTI. Of the 12 indicators, 8 were not correlated with use of commuter rail RTI ( $p>0.05$ ). Two indicators had statistically-significant differences in which non-users reported higher rankings ("Arriving at your destination on-time" and "Overall MBTA service"), and only two had statistically-significant differences in which the RTI user group reported higher levels of quality of service ("Amount of time between trains" in Table 4 and "Availability of real-time train information" in Table 5). The higher ranking of the availability of commuter rail RTI by its user group is intuitive, since those who use RTI are more likely to rank it favorably since they value it enough to use it. The positive correlation of RTI use with the indicator for the amount of time between trains suggests that respondents who use RTI do not experience as much time between trains or are not as concerned by the time between trains, and subsequently, they may perceive the frequency of service as higher quality, even though frequency has not changed. 
TABLE 4. Results of Quality-of-Service Analysis for Indicators \#1-6

\begin{tabular}{|c|c|c|c|c|c|c|}
\hline & $\begin{array}{l}\text { Non- } \\
\text { User }\end{array}$ & $\%$ & $\begin{array}{l}\text { RTI } \\
\text { User }\end{array}$ & $\%$ & $\begin{array}{l}\text { Total } \\
\text { Count }\end{array}$ & $\%$ \\
\hline Service Quality Ranking & \multicolumn{6}{|c|}{ \#1: On-time performance (reliability) } \\
\hline 1 - Poor & 31 & $5 \%$ & 15 & $5 \%$ & 46 & $5 \%$ \\
\hline 2 - Somewhat Poor & 77 & $13 \%$ & 36 & $12 \%$ & 113 & $13 \%$ \\
\hline 3 - Average & 201 & $34 \%$ & 128 & $43 \%$ & 329 & $37 \%$ \\
\hline 4-Good & 208 & $36 \%$ & 101 & $34 \%$ & 309 & $35 \%$ \\
\hline 5 - Excellent & 66 & $11 \%$ & 16 & $5 \%$ & 82 & $9 \%$ \\
\hline Total No. of Responses & 583 & $100 \%$ & 296 & $100 \%$ & 879 & $100 \%$ \\
\hline Percent Above Average & - & $47 \%$ & - & $40 \%$ & - & $44 \%$ \\
\hline Kruskal Wallis Test & \multicolumn{6}{|c|}{ Chi-squared $=3.5346, p$-value $=0.060$} \\
\hline Service Quality Ranking & \multicolumn{6}{|c|}{ \#2: How long you wait for train } \\
\hline 1 - Poor & 19 & $3 \%$ & 4 & $1 \%$ & 23 & $3 \%$ \\
\hline 2 - Somewhat Poor & 46 & $8 \%$ & 21 & $7 \%$ & 67 & $8 \%$ \\
\hline 3 - Average & 240 & $42 \%$ & 146 & $51 \%$ & 386 & $45 \%$ \\
\hline 4-Good & 201 & $35 \%$ & 105 & $36 \%$ & 306 & $36 \%$ \\
\hline 5 - Excellent & 63 & $11 \%$ & 13 & $4 \%$ & 76 & $9 \%$ \\
\hline Total No. of Responses & 569 & $100 \%$ & 289 & $100 \%$ & 858 & $100 \%$ \\
\hline Percent Above Average & - & $46 \%$ & - & $41 \%$ & - & $45 \%$ \\
\hline Kruskal Wallis Test & \multicolumn{6}{|c|}{ Chi-squared $=2.1997, p$-value $=0.138$} \\
\hline Service Quality Ranking & \multicolumn{6}{|c|}{ \#3: Amount of time between trains } \\
\hline 1 - Poor & 94 & $17 \%$ & 36 & $13 \%$ & 130 & $15 \%$ \\
\hline 2 - Somewhat Poor & 119 & $21 \%$ & 60 & $21 \%$ & 179 & $21 \%$ \\
\hline 3 - Average & 211 & $38 \%$ & 102 & $36 \%$ & 313 & $37 \%$ \\
\hline 4-Good & 98 & $18 \%$ & 66 & $23 \%$ & 164 & $19 \%$ \\
\hline 5 - Excellent & 38 & $7 \%$ & 22 & $8 \%$ & 60 & $7 \%$ \\
\hline Total No. of Responses & 560 & $100 \%$ & 286 & $100 \%$ & 846 & $100 \%$ \\
\hline Percent Above Average & - & $24 \%$ & - & $31 \%$ & - & $26 \%$ \\
\hline Kruskal Wallis Test & \multicolumn{6}{|c|}{ Chi-squared $=3.9373, p$-value $=0.047<0.05$} \\
\hline
\end{tabular}

\begin{tabular}{|c|c|c|c|c|c|}
\hline $\begin{array}{c}\text { Non- } \\
\text { User }\end{array}$ & $\%$ & $\begin{array}{c}\text { RTI } \\
\text { User }\end{array}$ & $\%$ & $\begin{array}{c}\text { Total } \\
\text { Count }\end{array}$ & $\%$ \\
\hline \multicolumn{7}{|c|}{ \#4: Arriving at your destination on time } \\
\hline 21 & $4 \%$ & 10 & $3 \%$ & 31 & $4 \%$ \\
\hline 69 & $12 \%$ & 37 & $13 \%$ & 106 & $12 \%$ \\
\hline 192 & $33 \%$ & 117 & $40 \%$ & 309 & $36 \%$ \\
\hline 214 & $37 \%$ & 104 & $36 \%$ & 318 & $37 \%$ \\
\hline 79 & $14 \%$ & 22 & $8 \%$ & 101 & $12 \%$ \\
\hline 575 & $100 \%$ & 290 & $100 \%$ & 865 & $100 \%$ \\
\hline- & $51 \%$ & - & $43 \%$ & - & $48 \%$ \\
\hline \multicolumn{7}{|c|}{ Chi-squared $=4.8031, p-v a l u e=0.028$} \\
\hline 3 & $1 \%$ & 3 & $1 \%$ & 6 & $1 \%$ \\
\hline 18 & $3 \%$ & 8 & $3 \%$ & 26 & $3 \%$ \\
\hline 125 & $22 \%$ & 65 & $23 \%$ & 190 & $22 \%$ \\
\hline 232 & $40 \%$ & 118 & $41 \%$ & 350 & $41 \%$ \\
\hline 197 & $34 \%$ & 93 & $32 \%$ & 290 & $34 \%$ \\
\hline 575 & $100 \%$ & 287 & $100 \%$ & 862 & $100 \%$ \\
\hline- & $75 \%$ & - & $74 \%$ & - & $74 \%$ \\
\hline \multicolumn{7}{|c|}{ \#ersonal safety at station } \\
\hline
\end{tabular}

Chi-squared $=0.2932, p$-value $=0.588$

\section{\#6: Availability of schedule and map information}

\begin{tabular}{|c|c|c|c|c|c|}
\hline 9 & $2 \%$ & 4 & $1 \%$ & 13 & $2 \%$ \\
\hline 18 & $3 \%$ & 8 & $3 \%$ & 26 & $3 \%$ \\
\hline 158 & $28 \%$ & 68 & $24 \%$ & 226 & $27 \%$ \\
\hline 190 & $34 \%$ & 100 & $35 \%$ & 290 & $34 \%$ \\
\hline 187 & $33 \%$ & 109 & $38 \%$ & 296 & $35 \%$ \\
\hline 562 & $100 \%$ & 289 & $100 \%$ & 851 & $100 \%$ \\
\hline- & $67 \%$ & - & $72 \%$ & - & $69 \%$ \\
\hline \multicolumn{6}{|c|}{ Chi-squared $=2.6342, p$-value $=0.105$} \\
\hline
\end{tabular}


TABLE 5. Results of Quality-of-Service Analysis for Indicators \#7-12

\begin{tabular}{|c|c|c|c|c|c|c|}
\hline & $\begin{array}{l}\text { Non- } \\
\text { User }\end{array}$ & $\%$ & $\begin{array}{l}\text { RTI } \\
\text { User }\end{array}$ & $\%$ & $\begin{array}{l}\text { Total } \\
\text { Count }\end{array}$ & $\%$ \\
\hline Service Quality Ranking & \multicolumn{6}{|c|}{$\begin{array}{l}\text { \#7: Availability of real-time train information } \\
\text { (web \& mobile) }\end{array}$} \\
\hline 1 - Poor & 37 & $9 \%$ & 7 & $2 \%$ & 44 & $6 \%$ \\
\hline 2 - Somewhat Poor & 50 & $12 \%$ & 23 & $8 \%$ & 73 & $11 \%$ \\
\hline 3 - Average & 182 & $45 \%$ & 113 & $40 \%$ & 295 & $43 \%$ \\
\hline 4- Good & 102 & $25 \%$ & 90 & $32 \%$ & 192 & $28 \%$ \\
\hline 5 - Excellent & 36 & $9 \%$ & 49 & $17 \%$ & 85 & $12 \%$ \\
\hline Total No. of Responses & 407 & $100 \%$ & 282 & $100 \%$ & 689 & $100 \%$ \\
\hline Percent Above Average & - & $34 \%$ & - & $49 \%$ & - & $40 \%$ \\
\hline Kruskal Wallis Test & \multicolumn{6}{|c|}{ Chi-squared $=24.9232, p$-value $=5.996 e-07$} \\
\hline Service Quality Ranking & \multicolumn{6}{|c|}{ \#8: Effectiveness of T-Alerts for incidents } \\
\hline 1 - Poor & 64 & $14 \%$ & 30 & $11 \%$ & 94 & $13 \%$ \\
\hline 2 - Somewhat Poor & 94 & $20 \%$ & 52 & $19 \%$ & 146 & $20 \%$ \\
\hline 3 - Average & 180 & $39 \%$ & 112 & $41 \%$ & 292 & $39 \%$ \\
\hline 4-Good & 99 & $21 \%$ & 61 & $22 \%$ & 160 & $22 \%$ \\
\hline 5 - Excellent & 28 & $6 \%$ & 21 & $8 \%$ & 49 & $7 \%$ \\
\hline Total No. of Responses & 465 & $100 \%$ & 276 & $100 \%$ & 741 & $100 \%$ \\
\hline Percent Above Average & - & $27 \%$ & - & $30 \%$ & - & $28 \%$ \\
\hline Kruskal Wallis Test & \multicolumn{6}{|c|}{ Chi-squared $=1.6292, p$-value $=0.202$} \\
\hline Service Quality Ranking & \multicolumn{6}{|c|}{$\begin{array}{l}\text { \#9: Explaining reasons for delays or } \\
\text { other problems }\end{array}$} \\
\hline 1 - Poor & 103 & $19 \%$ & 63 & $22 \%$ & 166 & $20 \%$ \\
\hline 2 - Somewhat Poor & 120 & $22 \%$ & 64 & $22 \%$ & 184 & $22 \%$ \\
\hline 3 - Average & 180 & $33 \%$ & 93 & $32 \%$ & 273 & $33 \%$ \\
\hline $4-$ Good & 103 & $19 \%$ & 54 & $19 \%$ & 157 & $19 \%$ \\
\hline 5 - Excellent & 35 & $6 \%$ & 14 & $5 \%$ & 49 & $6 \%$ \\
\hline Total No. of Responses & 541 & $100 \%$ & 288 & $100 \%$ & 829 & $100 \%$ \\
\hline Percent Above Average & - & $26 \%$ & - & $24 \%$ & - & $25 \%$ \\
\hline Kruskal Wallis Test & \multicolumn{6}{|c|}{ Chi-squared $=1.0423, p$-value $=0.307$} \\
\hline
\end{tabular}

\begin{tabular}{|c|c|c|c|c|c|}
\hline $\begin{array}{l}\text { Non- } \\
\text { User }\end{array}$ & $\%$ & $\begin{array}{l}\text { RTI } \\
\text { User }\end{array}$ & $\%$ & $\begin{array}{l}\text { Total } \\
\text { Count }\end{array}$ & $\%$ \\
\hline \multicolumn{6}{|c|}{ \#10: Overall commuter rail service on THIS line } \\
\hline 13 & $2 \%$ & 9 & $3 \%$ & 22 & $3 \%$ \\
\hline 58 & $10 \%$ & 23 & $8 \%$ & 81 & $9 \%$ \\
\hline 181 & $32 \%$ & 108 & $38 \%$ & 289 & $34 \%$ \\
\hline 242 & $42 \%$ & 117 & $41 \%$ & 359 & $42 \%$ \\
\hline 77 & $13 \%$ & 29 & $10 \%$ & 106 & $12 \%$ \\
\hline 571 & $100 \%$ & 286 & $100 \%$ & 857 & $100 \%$ \\
\hline- & $56 \%$ & - & $51 \%$ & - & $54 \%$ \\
\hline \multicolumn{6}{|c|}{ Chi-squared $=1.6284, p$-value $=0.202$} \\
\hline \multicolumn{6}{|c|}{ \#11: Overall commuter rail service on ALL lines } \\
\hline 9 & $2 \%$ & 5 & $2 \%$ & 14 & $2 \%$ \\
\hline 41 & $10 \%$ & 16 & $7 \%$ & 57 & $9 \%$ \\
\hline 181 & $44 \%$ & 114 & $53 \%$ & 295 & $47 \%$ \\
\hline 148 & $36 \%$ & 72 & $33 \%$ & 220 & $35 \%$ \\
\hline 33 & $8 \%$ & 9 & $4 \%$ & 42 & $7 \%$ \\
\hline 412 & $100 \%$ & 216 & $100 \%$ & 628 & $100 \%$ \\
\hline- & $44 \%$ & - & $38 \%$ & - & $42 \%$ \\
\hline \multicolumn{6}{|c|}{ Chi-squared $=1.5283, p$-value $=0.216$} \\
\hline \multicolumn{6}{|c|}{$\begin{array}{l}\text { \#12: Overall MBTA service } \\
\text { (subway, bus, commuter rail) }\end{array}$} \\
\hline 16 & $3 \%$ & 7 & $3 \%$ & 23 & $3 \%$ \\
\hline 58 & $11 \%$ & 35 & $13 \%$ & 93 & $11 \%$ \\
\hline 238 & $44 \%$ & 137 & $51 \%$ & 375 & $46 \%$ \\
\hline 196 & $36 \%$ & 85 & $31 \%$ & 281 & $35 \%$ \\
\hline 34 & $6 \%$ & 7 & $3 \%$ & 41 & $5 \%$ \\
\hline 542 & $100 \%$ & 271 & $100 \%$ & 813 & $100 \%$ \\
\hline- & $42 \%$ & - & $34 \%$ & - & $40 \%$ \\
\hline
\end{tabular}




\section{Limitations and Future Research}

A few caveats limit the results of this exploratory study, and many areas for future research can be identified based on the results.

One noteworthy limitation of the on-board sampling method was that the response rate of the survey was not measured due to manpower constraints and the difficulty distributing surveys in crowded train cars. Another limitation of this study is that the accuracy of RTI was not monitored during the study period, which could have been done by comparing real-time arrival predictions to actual train arrival times. Because 21 percent of surveyed riders who do not use commuter rail RTI stated that commuter rail RTI is not accurate, further study should be conducted in the area of data accuracy and its impact on passengers.

In terms of future research, to expand upon this research design, riders on other commuter rail lines in Boston or on commuter rail systems in other cities could be surveyed to identify trends in the use and benefits of commuter rail RTI. Additionally, the sampling frame could include travelers using other forms of transportation who may switch modes due to the possible conveniences afforded by the provision of RTI. This is particularly important area for future research because many rail providers want to understand if providing RTI increases rail ridership, which might occur in the long term.

The analysis of RTI utilization could be expanded in numerous ways. First, future research could assess disaggregate trends (i.e., RTI queries by line, station-specific RTI queries) using fine-grained, server-side data by working with RTI application developers. Similarly, as of October 2014, there were 80+ different applications that provide transit information in the Boston region, and these applications could be compared to assess the quality of information presentation and corresponding effects on users. Another area for future research is comparing the utilization of RTI with both schedules and service alerts, particularly when there are differing levels of delays in transit service.

There also are avenues for additional research pertaining to both the wait time and quality of service analyses. The finding that use of RTI is associated with reduced usual wait times relied on self-reported data. For more concrete measurements, wait time observations should be conducted and repeated over time, which may also distinguish between differences in perceived and actual wait times. Additionally, the quality-of-service analysis could be expanded using multivariate techniques, such as factor analysis, to tease out the many factors that affect a rider's ranking of quality of service.

\section{Conclusions}

This research sheds light on the use of RTI on commuter rail services, offering initial insights on overall utilization of RTI, the relationship between RTI and passenger wait times, and the relationship between RTI and indicators of quality of service.

One year after the release of real-time data for Boston's commuter rail, one-third of commuter rail riders used RTI either sometimes/often/always, despite the fact that commuter rail RTI had not been formally marketed by the MBTA or MBCR. However, on a daily basis, the percentage of surveyed riders using commuter rail RTI was much lower, with only 5.5 percent of riders using RTI on the days the survey was conducted. Additionally, 
a large amount of overlap exists between riders who use commuter rail, bus, and subway RTI, which may be attributable to applications that integrate information from all three modes.

Two analyses of passenger wait times produced interesting results. First, wait times on the day of the survey were compared between passengers who used commuter rail RTI before boarding the train and those who did not, but the results did not support the hypothesis that RTI use lowers wait times. This may be partially attributed to the fact that there were no delays on the days when the survey was administered, and subsequently, passengers who consulted RTI before boarding would have seen the same information as passengers who consulted schedules. Conversely, the analysis of "usual" wait times showed that use of commuter rail RTI was associated with a decrease in self-reported usual wait times. This statistically-significant finding may capture the difference that RTI has on wait times over an extended period of time, since passengers who sometimes/often/always consult RTI can adjust their wait times on days when commuter rail service is delayed. Alternatively, it may be a difference in the perception of wait time attributable to RTI, since all wait time measures were self-reported.

An analysis of 12 quality of service indicators showed limited relationship with the use of commuter rail RTI. The only noteworthy finding is the positive correlation of RTI use with the indicator for the amount of time between trains, suggesting that respondents who use RTI do not experience as much time between trains or are not as concerned by the time between trains. The limited relationship between RTI use and the various quality-of-service indicators suggests minimal impacts of RTI on rider satisfaction with commuter rail service.

Overall, the results suggest that the benefits of commuter rail RTI are modest. This could be due to commuter rail's relatively high levels of on-time performance, the common practice of passengers consulting commuter rail schedules, the regularity of travel patterns among commuting riders, and/or users' limited possibilities to seek out wait time activities due to the design or location of stations. Transit providers may look to invest elsewhere if providing RTI to commuter rail passengers would be a costly endeavor. However, despite the modest benefits, many commuter rail riders choose to use this new information source, which may be due to generally increased expectations for refined, personalized transportation information sources. Therefore, where RTI is easily provided, agencies should consider offering it along with bus and rail RTI to provide a seamless information experience for the whole transit trip.

\section{Acknowledgments}

This research was funded by a Rappaport Institute Public Policy Summer Fellowship, the Singapore MIT Alliance for Research and Technology, a US DOT Eisenhower fellowship, a WTS Boston Fellowship, and a University Transportation Center grant. Sincere thanks to Jake Sion and Sam Jordan for their help coding the survey data and to the MIT student volunteers who helped distribute the surveys. Thanks also to Gregory Macfarlane at Georgia Tech for his guidance on robust regression; Professor David Weil, Professor Archon Fung, and Mary Graham of the Transparency Policy Project at the Harvard Ken- 
nedy School Ash Center for Democratic Governance and Innovation for their support of the project; and Michael Lambert at the MBTA for reviewing the paper.

\section{References}

American Public Transportation Association (APTA). 2012. 2012 Public Transportation Fact Book 63nd Edition. Washington, DC.

Brakewood, C. 2014. Publications. http://candacebrakewood.files.wordpress. com/2013/09/6-4-2012-inbound_worcester_survey_questionnaire.pdf. Accessed October 21, 2014.

Brakewood, C., S. Barbeau, and K. Watkins. 2014. An experiment evaluating the impacts of real-time transit information on bus riders in Tampa, Florida. Transportation Research Part A: Policy and Practice 69: 409-422.

Brakewood, C., F. Rojas, J. K. Robin, J. Sion, and S. Jordan. 2014. Forecasting mobile ticketing adoption on commuter rail. Journal of Public Transportation 17.1: 1-19.

Carrel, A., A. Halvorsen, and J. L. Walker. 2013. Passengers' perception of and behavioral adaptation to unreliability in public transportation. Transportation Research Record 2351: 153-162.

Cats, O., H. N. Koutsopoulos, W. Burghout, and T. Toledo. 2011. Effect of real-time transit information on dynamic path choice of passengers. Transportation Research Record 2217: 46-54.

Central Transportation Planning Staff (CTPS). 2010. Commuter rail all lines 2008-09. MBTA Systemwide Passenger Survey. http://www.ctps.org/drupal/data/pdf/studies/ transit/MBTA_Passenger_Survey/Commuter_Rail_Volume.pdf. Accessed July 26, 2013.

Ferris, B., K. Watkins, and A. Borning. (2010). OneBusAway: Results from providing realtime arrival information for public transit. Proceedings: $\mathrm{CHI}$ : 1807-1816.

Fries, R. N., A. E. Dunning, and M. A. Chowdhury. 2011. University traveler value of potential real-time transit information. Journal of Public Transportation, 14(2): 29-50.

Gooze, A., K. E. Watkins, and A. Borning. 2013. Benefits of real-time transit information and impacts of data accuracy on rider experience. Transportation Research Record 2351: 95-103.

Massachusetts Bay Transportation Authority (MBTA). 2013. Introducing the new T-alerts. http://www.mbta.com/rider_tools/t_alerts/. Accessed July 26, 2013.

Massachusetts Bay Transportation Authority (MBTA). 2014. App showcase. http://mbta. com/rider_tools/apps/ Accessed October 25, 2014.

Massachusetts Bay Transportation Authority (MBTA). 2010. Ridership and Service Statistics, Thirteenth Edition, 2010. http://www.mbta.com/uploadedfiles/ documents/Bluebook\%202010.pdf. Accessed July 26, 2013. 
Massachusetts Bay Transportation Authority (MBTA). 2012. Scorecard: July 2012. http:// www.mbta.com/uploadedfiles/About_the_T/Score_Card/ScoreCard\%202012-07. pdf. Accessed November 11, 2013.

Massachusetts Department of Transportation (MassDOT). 2013. MassDOT developers page. http://www.massdot.state.ma.us/DevelopersData.aspx. Accessed July 26, 2013.

Metra. 2013. Real-Time Tracker. http://metrarail.com/metra/en/home.html. Accessed July 25, 2013.

Metropolitan Transportation Authority (MTA). 2013a. LIRR train time pilot program. http://wx3.lirr.org/lirr/TrainTime/. Accessed July 25, 2013.

Metropolitan Transportation Authority (MTA). 2013b. Metro-North train time! http://m. mta.info/mt/as0.mta.info/mnr/mstations/default.cfm. Accessed July 25, 2013.

New Jersey Transit. 2013. Departure Vision. http://dv.njtransit.com/mobile/tid-mobile. aspx?sid=AZ. Accessed July 25, 2013.

Pew Research Internet Project. 2012. Nearly half of American adults are smartphone owners. http://www.pewinternet.org/2012/03/01/nearly-half-of-american-adults-aresmartphone-owners/. Accessed October 22, 2014.

Rojas, F.. 2012. Transit transparency: Effective disclosure through open data. Transparency Policy Project, Harvard Kennedy School. http://www.transparencypolicy.net/assets/ FINAL_UTC_TransitTransparency_8\%2028\%202012.pdf. Accessed July 26, 2013.

Schweiger, C. 2011. TCRP Synthesis 91: Use and deployment of mobile device technology for real-time transit information. Transportation Research Board, Washington, DC.

Tang, L., H. Ross, and X. Han. 2013. Substitution or complementarity: An examination of the ridership effects of real-time bus information on transit rail in the city of Chicago. Proceedings of the 92nd TRB Annual Meeting, Washington, DC.

Tang, L., and P. Thakuriah. 2010. Will the psychological effects of real-time transit information systems lead to ridership gain? Proceedings of the TRB 90th Annual Meeting, Washington, DC.

Tang, L., and P. Thakuriah. 2012. Ridership effects of real-time bus information system: A case study in the city of Chicago. Transportation Research Part C 22: 141-161.

Watkins, K., B. Ferris, A. Borning, S. Rutherford, and D. Layton. 2011. Where is my bus? Impact of mobile real-time information on the perceived and actual wait time of transit riders. Transportation Research Part A 45: 839-848.

Zhang, F., Q. Shen, and K. Clifton. 2008. Examination of traveler responses to real-time information about bus arrivals using panel data. Transportation Research Record 2082: 107-115. 


\section{About the Authors}

Dr. Candace Brakewood (cbrakewood@ccny.cuny.edu) is an Assistant Professor of Civil Engineering at the City College of New York. Her research focuses on public transportation, transportation planning, and intelligent transportation systems.

DR. FrancisCa Rojas (franciscar@iadb.org) is an Urban Development Specialist at the Inter-American Development Bank. Previously, she was Research Director with the Transparency Policy Project at the Kennedy School of Government at Harvard University.

Dr. P. Christopher Zegras (czegras@mit.edu) is an Associate Professor of Urban Planning at Massachusetts Institute of Technology. His teaching and research interests include the inter-relationships between transportation and the built and natural environments, transportation system finance and policy, and integrated system modeling.

DR. KARI WATKINS (kariwatkins@ce.gatech.edu) is an Assistant Professor of Civil Engineering at Georgia Institute of Technology. Her teaching and research interests revolve around multi-modal transportation planning and the use of technology in transportation, especially as related to transit planning and operations and improved traveler information.

JosHUA RoBIN (josh.robin@masabi.com) is Masabi's Vice President for Strategy and Development - North America, where he is responsible for working with U.S. transit agencies to deploy Masabi's mobile ticketing and agile fare collection systems. Prior to joining Masabi, he was the Director of Innovation for the MBTA in Boston. 